Research Article

\title{
Circularly Polarized Antenna Array Fed by Air-Bridge Free CPW-Slotline Network
}

\author{
Yilin Liu, Kama Huang, and Xia Luo \\ College of Electronics \& Information Engineering, Sichuan University, Chengdu 610065, China \\ Correspondence should be addressed to Kama Huang; huangkamascu@21cn.com
}

Received 11 January 2017; Accepted 13 March 2017; Published 4 May 2017

Academic Editor: Symeon Nikolaou

Copyright (C) 2017 Yilin Liu et al. This is an open access article distributed under the Creative Commons Attribution License, which permits unrestricted use, distribution, and reproduction in any medium, provided the original work is properly cited.

\begin{abstract}
A novel design of $1 \times 2$ and $2 \times 2$ circularly polarized $(\mathrm{CP})$ microstrip patch antenna arrays is presented in this paper. The two CP antenna arrays are fed by sequentially rotated coplanar waveguide (CPW) to slotline networks and are processed on $1 \mathrm{~mm}$ thick single-layer FR4 substrates. Both of the two arrays are low-profile and lightweight. An air-bridge free CPW-slotline power splitter is appropriately designed to form the feeding networks and realize the two CP antenna arrays. The mechanism of circular polarization in this design is explained. The simulated and measured impedance bandwidths as well as the $3 \mathrm{~dB}$ axial ratio bandwidths and the radiation patterns of the two proposed antenna arrays are presented. This proposed design can be easily extended to form a larger plane array with good performance owing to its simple structure.
\end{abstract}

\section{Introduction}

Circular polarization is desired for many radio systems, such as mobile satellite communication, intelligent transportation, and microwave power transmission (MPT) systems $[1,2]$. Single-layer planar CP antennas are suitable for those systems due to their low profile, light weight, and possible conformity to the curved surface of aircrafts [3]. In addition, CP antennas also have the advantages of reducing multipath effects and avoiding polarization alignment between the transmitting antenna and the receiving antenna [4]. Generally, CP wave can be excited by two orthogonal electric field components that are with equal amplitude and 90 degrees' phase difference. Perturbation technique is commonly used on microstrip antenna to excite CP wave, such as loading with truncation corners [5], as well as etching slots on the antenna patch [6]. Nevertheless, one well-known disadvantage of those microstrip antennas is their rather limited $3 \mathrm{~dB}$ axial ratio (AR) bandwidths (only about $1 \%$ ). Multiple substrate layer technique is one of the most common methods to improve the $3 \mathrm{~dB}$ AR bandwidth $[7,8]$. Unfortunately, this approach, which requires complicated antenna structures, will not only increase the profiles of antennas and make heat trapped in the middle of the boards, but also increase the manufacturing costs.

The coplanar waveguide (CPW) has gained increasing popularity in recent years, since it has several advantages over traditional microstrip line, such as easy integration with active and passive elements, high circuit density, low dispersion, low radiation loss, and avoidance of ground vias. However, the use of CPW in antenna design has not been widespread. Most CPW is used for slot antennas and printed monopoles in the previously published papers [9-11]. Owing to the characteristics of compact size, wide $\mathrm{CP}$ bandwidth, and omnidirectional radiation patterns, those kinds of antennas fit very well for conformal packaging and for wearable electronics [12, 13]. However, slot antennas and monopoles have quite low gains and are not suitable for directional microwave transmission. Additionally, CPW has been rarely applied to feed antenna arrays till now $[14,15]$.

In this paper, a $1 \times 2$ sequentially rotated patch antenna array fed by a CPW-slotline network is firstly proposed. The measurement results of this linear array show that the $3 \mathrm{~dB}$ axial ratio (AR) bandwidth and the impedance bandwidth are $3.79 \%$ and $16.41 \%$, respectively. Furthermore, based on the 


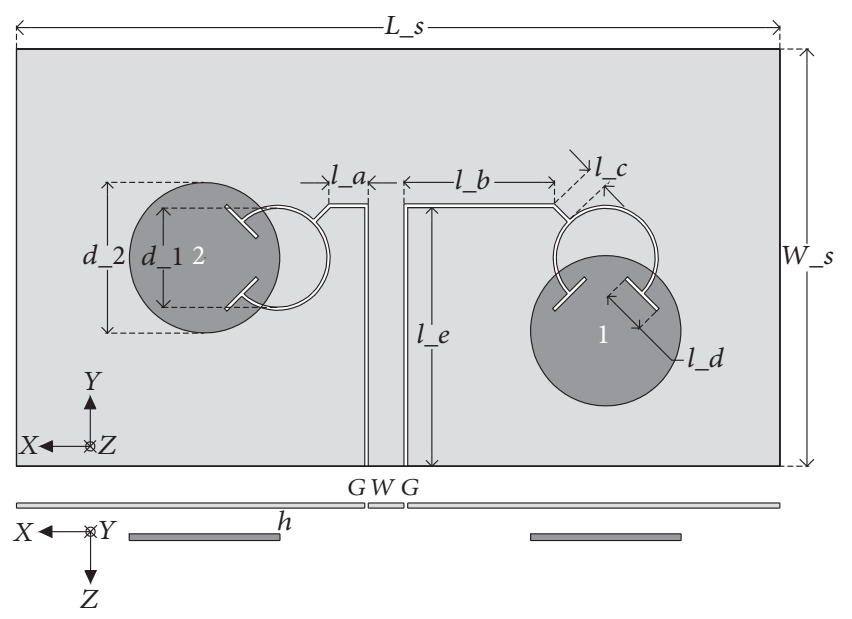

FIGURE 1: The geometry of the $1 \times 2$ linear antenna array.

initial linear array, an improved $2 \times 2$ array with a $6.91 \% 3 \mathrm{~dB}$ AR bandwidth and a $14.74 \%$ impedance bandwidth is realized by using a bridgeless CPW power divider. Both of the two arrays can provide considerable $3 \mathrm{~dB} \mathrm{AR}$ bandwidth and what is needed is only a single-layer substrate. Moreover, because of the low-profile substrate and the less usage of metal, the two arrays are very lightweight, only about $0.211 \mathrm{~g} / \mathrm{cm}^{2}$. It is a big advantage for aerospace applications.

\section{2. $1 \times 2$ Sequentially Rotated Linear Antenna Array Design}

The geometry of the $1 \times 2$ linear antenna array is shown in Figure 1. Antenna patches and the CPW-slot feeding network are, respectively, placed on the opposite sides of the substrate. Ring-shaped slotline structures with transverse end slots are used to connect with and feed the patches. The FR4 substrate, $h=1 \mathrm{~mm}$ and $\varepsilon_{r}=4.4$, is used in experiments and all arrays are simulated by the ANSYS HFSS 15.0.

At the beginning of the $1 \times 2$ linear array design, the widths of the strip and slot of the CPW are set to be $3 \mathrm{~mm}$ and $0.3 \mathrm{~mm}$, respectively, to make sure that the characteristic impedance of the CPW is $50 \Omega$. The slotline, connecting the CPW with the ring-slot structures, is kept at $0.3 \mathrm{~mm}$ width to ensure that its characteristic impedance is $100 \Omega$. Therefore, the T-shaped CPW-to-slotlines transition can be matched. Circular antenna patches are dual-fed by compact ring-slot structures. The dual-fed method shows a more stable performance than the perturbation method on increasing the $3 \mathrm{~dB}$ AR bandwidth. By selecting suitable radius, the ringslots can excite two orthogonal current components with the same magnitude on the patch surfaces for CP radiation. In accordance with the sequential rotation principles, the feeding network should be adjusted to provide proper spatial rotation and phase compensation for the left-hand circularly polarized (LHCP) $1 \times 2$ linear array. Each element of antenna 2 , including the patch and the ring-slot feeding structure, is physically rotated 90 degrees clockwise from the previous element. Furthermore, to ensure the in-phase radiation of
TABLE 1: The optimal parameters of the $1 \times 2$ linear array (unit: $\mathrm{mm}$ ).

\begin{tabular}{lc}
\hline$h$ & 1 \\
$G$ & 0.30 \\
$W$ & 3 \\
$W \_s$ & 35 \\
$L \_s$ & 65 \\
$l \_a$ & 3.30 \\
$l \_b$ & 12.25 \\
$l \_c$ & 1.85 \\
$l \_d$ & 3.61 \\
$l \_e$ & 21.70 \\
$d \_1$ & 8.62 \\
$d \_2$ & 13.09 \\
\hline
\end{tabular}

the two patches after the rotation, a 90-degree phase delay slotline is inserted before feeding patch 1 . An important strength of the sequential rotation feeding technique is that the reflections caused by mismatched elements can cancel each other out at the corporate feed input terminal $[16,17]$. Therefore, sequential rotation architecture can improve both $3 \mathrm{~dB}$ AR bandwidth and impedance bandwidth of CP antenna arrays. The optimal parameters of the $1 \times 2$ linear array are shown in Table 1.

\section{3. $2 \times 2$ Antenna Array Design}

Since CPW feeding network is a difficulty in the design of CPW-fed arrays, only a few researches focus on it. The normal CPW feeding network needs CPW feeding lines with different characteristic impedance as well as the transition structures between them [18]. Those requirements will enlarge the size of the feeding network and make it even more complicated when designing large scale antenna arrays. To reduce the complexity of CPW feeding network design, a $3 \mathrm{~dB}$ $\mathrm{CPW}$ power splitter is needed. The most common $3 \mathrm{~dB} \mathrm{CPW}$ power splitter needs multiple substrate layers and air-bridges, resulting in the difficulty to machine and weigh increment of the antenna arrays [19].

In this paper, a modulated $3 \mathrm{~dB} C \mathrm{CPW}$ power splitter is used for feeding network design. This kind of CPW power splitter is firstly proposed in [20]; its geometry is shown in Figure 2. The CPW power splitter is bridgeless and consists of one CPW-to-slotline T-junction and two slotline-to-CPW transition structures; the characteristic impedance of CPW and slot feeding lines is set to $50 \Omega$ and $100 \Omega$, respectively. At the CPW-to-slotline T-junction, the input power is equally divided into two $100 \Omega$ slotlines and then is transmitted to two output ports through the slotline-to-CPW transition structures. Figure 3 shows the simulated current distributions under the optimized structure and the preliminary simulated $S$-parameters of the power divider are shown in Figure 4. This simulation is carried out just to show that this kind of power splitter can be a good basal element for furtherdesigned arrays. However, in the next steps, a modification will be performed for the whole feeding network of the $2 \times 2$ 


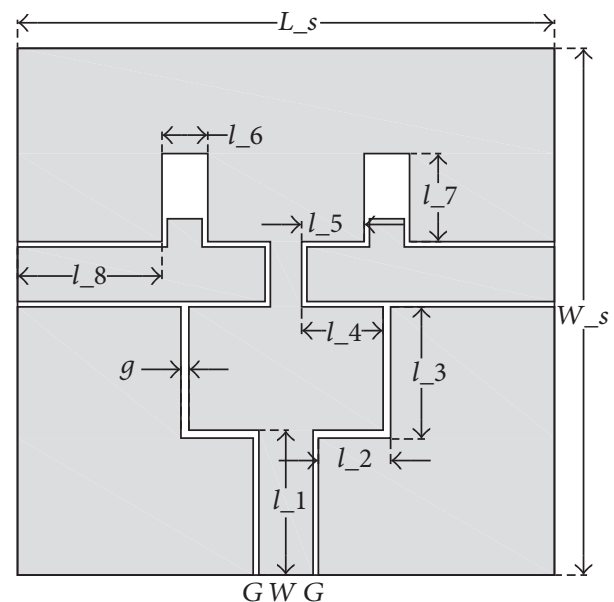

Figure 2: The geometry of the $3 \mathrm{~dB}$ CPW power splitter.

TABLE 2: The optimal parameters of the 3-dB CPW power splitter (unit: $\mathrm{mm}$ ).

\begin{tabular}{lc}
\hline$h$ & 1 \\
$G$ & 0.30 \\
$W$ & 3 \\
$W \_s$ & 29 \\
$L \_s$ & 30 \\
$l \_1$ & 8.11 \\
$l \_2$ & 3.86 \\
l_3 & 7.28 \\
l_4 & 4.49 \\
l_5 & 3.47 \\
l_6 & 2.48 \\
l_7 & 4.87 \\
l_8 & 8.05 \\
$g$ & 0.44 \\
\hline
\end{tabular}

antenna array. The parameters of the $3 \mathrm{~dB} C P W$ power splitter are shown in Table 2.

By integrating the $1 \times 2$ linear array with the $3 \mathrm{~dB} C P W$ power splitter, a $2 \times 2$ plane array can be realized. To ensure the in-phase radiation of the two linear $1 \times 2$ arrays, a 180degree phase delay CPW feeding line is inserted before feeding patch 1 and patch 2 . The whole CPW-slotline feeding network is simple and bridgeless. What is more, the $2 \times 2$ array can be extended to form a larger 2-dimensional AR array on a single thin substrate by repeating the CPW-slotline feeding network. The geometry of the $2 \times 2$ antenna array is presented in Figure 5 and the optimized parameters of this array are shown in Table 3.

\section{Experiment Results}

By using design parameters obtained in the previous section, a $1 \times 2$ linear array and a $2 \times 2$ array are fabricated on FR4 substrate, respectively. Figures 6 and 7 are the photographs of the two fabricated arrays.
TABLE 3: The optimal parameters of the $2 \times 2$ array (unit: $\mathrm{mm}$ ).

\begin{tabular}{|c|c|}
\hline$h$ & 1 \\
\hline$G$ & 0.3 \\
\hline$W$ & 3 \\
\hline$W \_s$ & 74 \\
\hline$L \_s$ & 85 \\
\hline l_a & 5.25 \\
\hline$l \_b$ & 14.43 \\
\hline$l \_c$ & 2 \\
\hline$l \_d$ & 3.52 \\
\hline l_e & 22.34 \\
\hline$l \_f$ & 4.70 \\
\hline l_1 & 30 \\
\hline l_2 & 4 \\
\hline l_3 & 6.82 \\
\hline l_4 & 4.21 \\
\hline l_5 & 3.47 \\
\hline l_6 & 2.52 \\
\hline l_7 & 4.87 \\
\hline$g$ & 0.43 \\
\hline$d \_1$ & 9.36 \\
\hline$d \_2$ & 13.23 \\
\hline
\end{tabular}

The measured and simulated $\left|S_{11}\right|$ and AR of the $1 \times$ 2 linear array are shown in the solid and dashed lines of Figures 8 and 9, respectively. Because of the mechanical tolerance, such as the machining error in the width of the microstrip feed line, the discrepancies still remain. Besides, the welds between the SMA connector and the CPW structure may probably cause discrepancies as well. However, a good agreement between measured and simulated results can be achieved. The measured $3 \mathrm{~dB}$ AR bandwidth of the $1 \times 2$ linear array is $3.79 \%$ from $5.69 \mathrm{GHz}$ to $5.91 \mathrm{GHz}$, and the measured impedance bandwidth is $16.41 \%$ from $5.37 \mathrm{GHz}$ to $6.33 \mathrm{GHz}$. The $\left|S_{11}\right|$ is lower than $-10 \mathrm{~dB}$ over the whole $3 \mathrm{~dB}$ AR bandwidth.

Figures 10 and 11 compare the measured and simulated $\left|S_{11}\right|$ and AR of the $2 \times 2$ array in the solid and dashed lines, respectively. As in the case of the $1 \times 2$ linear array, the discrepancy is probably caused by the fabrication errors existing in the test piece and by the welds between the SMA connector and the CPW structure. The measured $3 \mathrm{~dB} A R$ bandwidth of the $2 \times 2$ array is $6.91 \%$ from $5.59 \mathrm{GHz}$ to $5.99 \mathrm{GHz}$ and the measured impedance bandwidth is $14.74 \%$ from $5.53 \mathrm{GHz}$ to $6.41 \mathrm{GHz}$. The $\left|S_{11}\right|$ is lower than $-10 \mathrm{~dB}$ over the whole $3 \mathrm{~dB}$ AR bandwidth. Due to the bandwidth limitation of the CPW power splitter, there is a reduction in impedance bandwidth when forming the $2 \times 2$ array.

The radiation patterns of the two array prototypes are measured by using a linear polarization auxiliary horn antenna. This method is based on the decomposition theory of the ellipse polarization microwave. Through three or more measurements at different angles by using the linear polarization auxiliary antenna, the radiation patterns and the AR against azimuth angle of CP antennas can be obtained [21]. Figures 12 and 13 depict the simulated and measured 

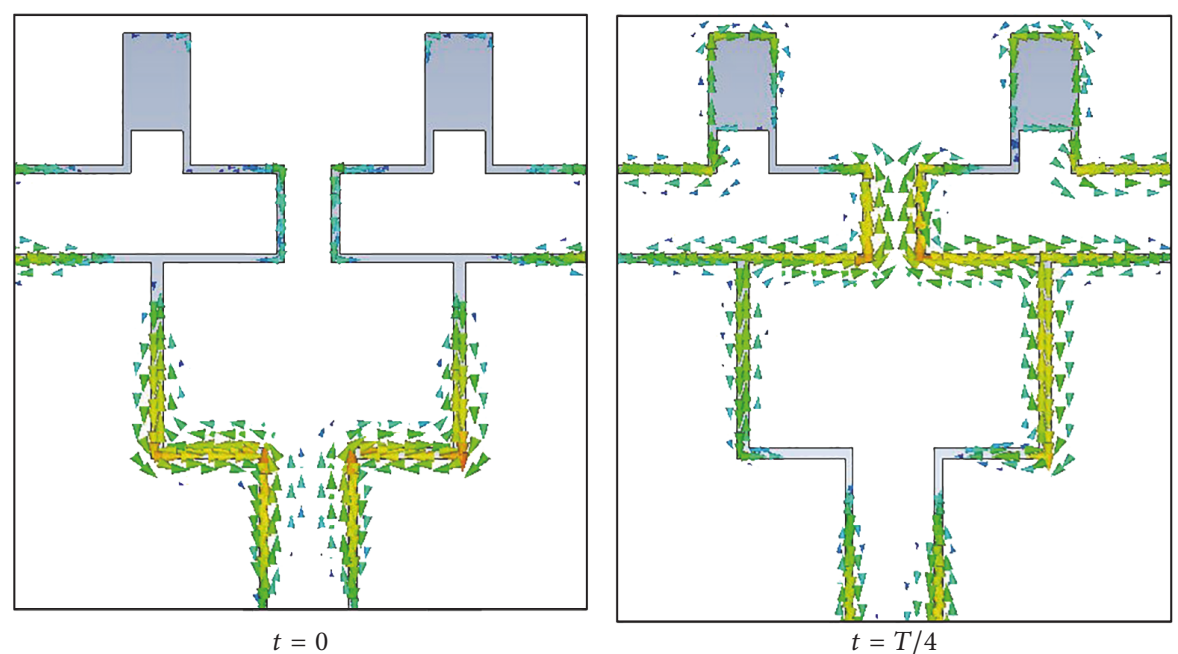

FIgURE 3: The simulated current distributions under the optimized structure.

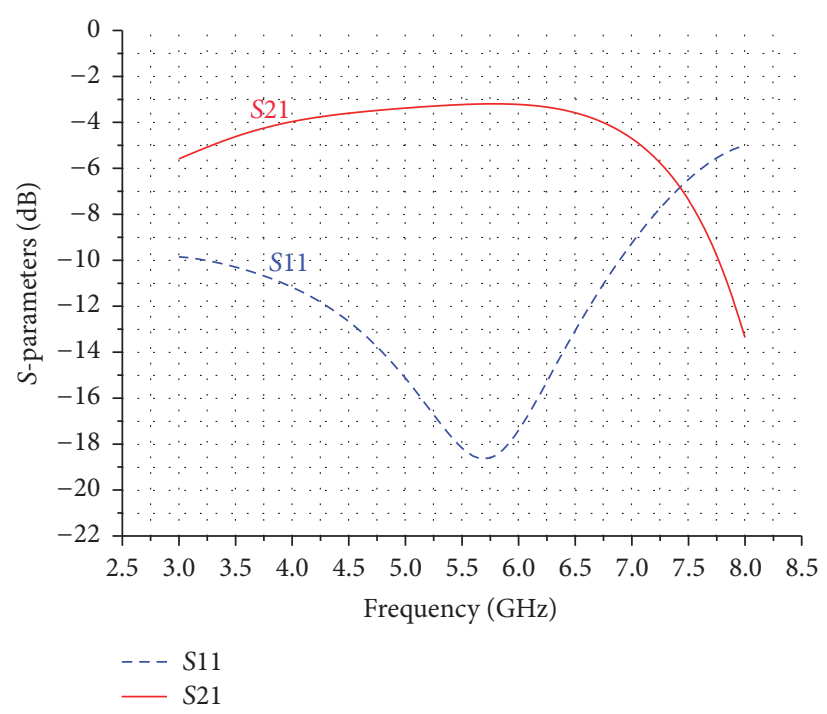

Figure 4: Simulated S-parameters of the $3 \mathrm{~dB} C P W$ power splitter.

radiation patterns of the $1 \times 2$ linear array and $2 \times 2$ array in the $x-z($ phi $=0)$ and $y-z($ phi $=90)$ planes at the center frequency $5.8 \mathrm{GHz}$, respectively. It is observed that the measured main beams are in the $+z$ direction, and these two arrays are broadside antenna arrays. Figures 12 and 13 also depict the copolar and cross-polar components of those radiation patterns. The measured $\mathrm{AR}$ against azimuth angle of the two arrays in the $x-z(\mathrm{phi}=0)$ and $y-z(\mathrm{phi}=90)$ planes at the center frequency $5.8 \mathrm{GHz}$ are shown in Figures 14 and 15. It can be observed that the CP microwaves are radiated to $+z$ directions.

The array gains are measured by using the substitution method with a horn antenna of known gain. Figures 16 and 17, respectively, show the results of the LHCP gains and RHCP gains of the $1 \times 2$ linear array and the $2 \times 2$ array in the boresight direction. Figure 18 depicts the radiation efficiencies of the two proposed arrays. The maximum theoretical directivities in the $3 \mathrm{~dB}$ AR bandwidth are $8.51 \mathrm{~dB}$ and $11.37 \mathrm{~dB}$ for the $1 \times 2$ and $2 \times 2$ arrays, respectively. The maximum corresponding measured gains are $7.54 \mathrm{~dB}$ and $10.11 \mathrm{~dB}$ for the $1 \times 2$ and $2 \times 2$ arrays, respectively. The proposed design can be used as a unit block to form a larger array, as a higher gain level is required.

In order to further evaluate the performance of the proposed arrays, a comparison between the $2 \times 2$ array and other similar arrays is shown in Table 4 . It can be observed that the proposed $2 \times 2$ array has an adequate gain within an adequate frequency bandwidth. 


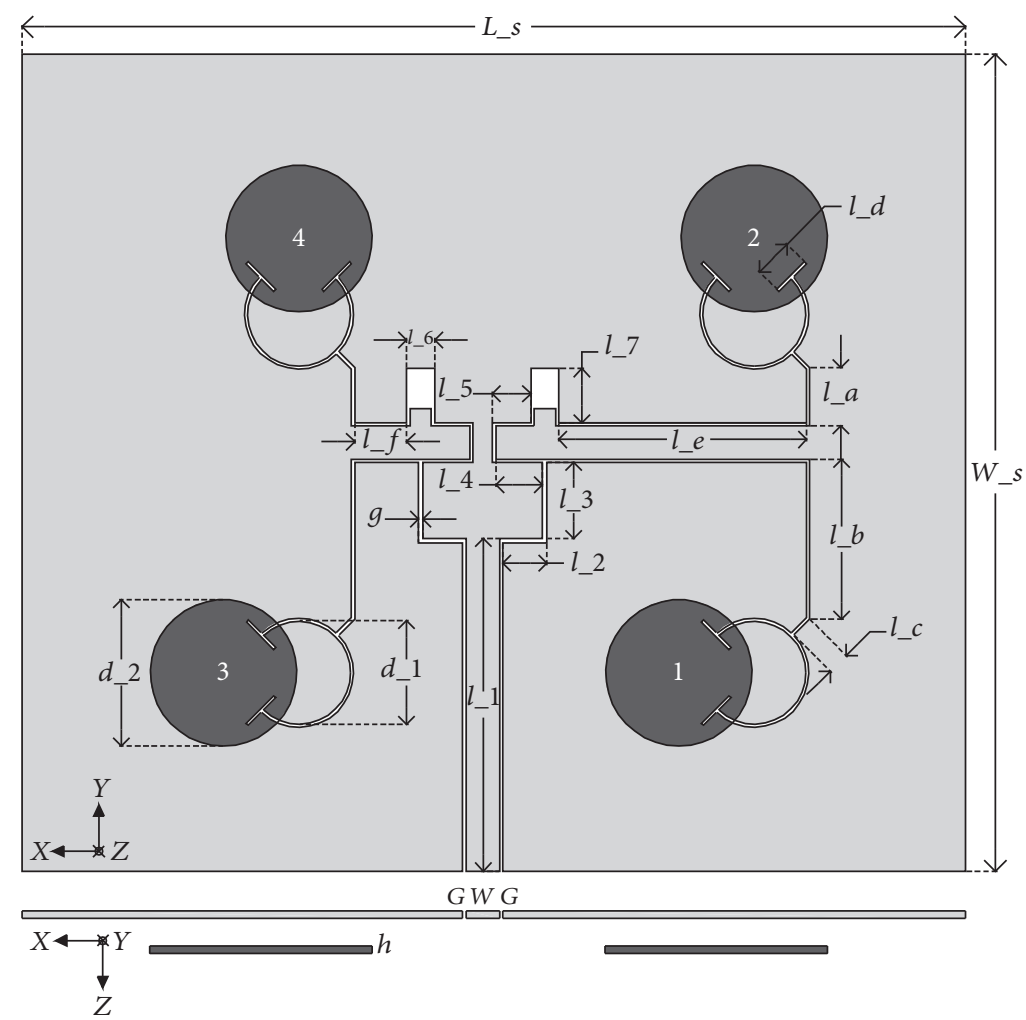

FIGURE 5: The geometry of the $2 \times 2$ antenna array.

Top view

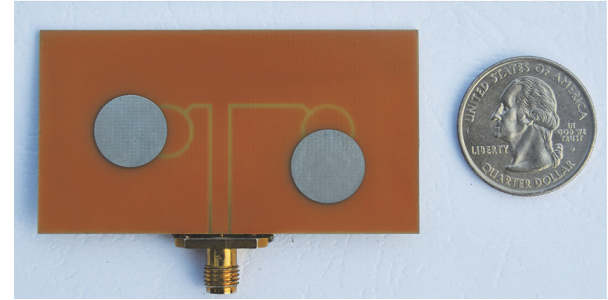

Figure 6: Top view and bottom view of the $1 \times 2$ linear array.

Top view
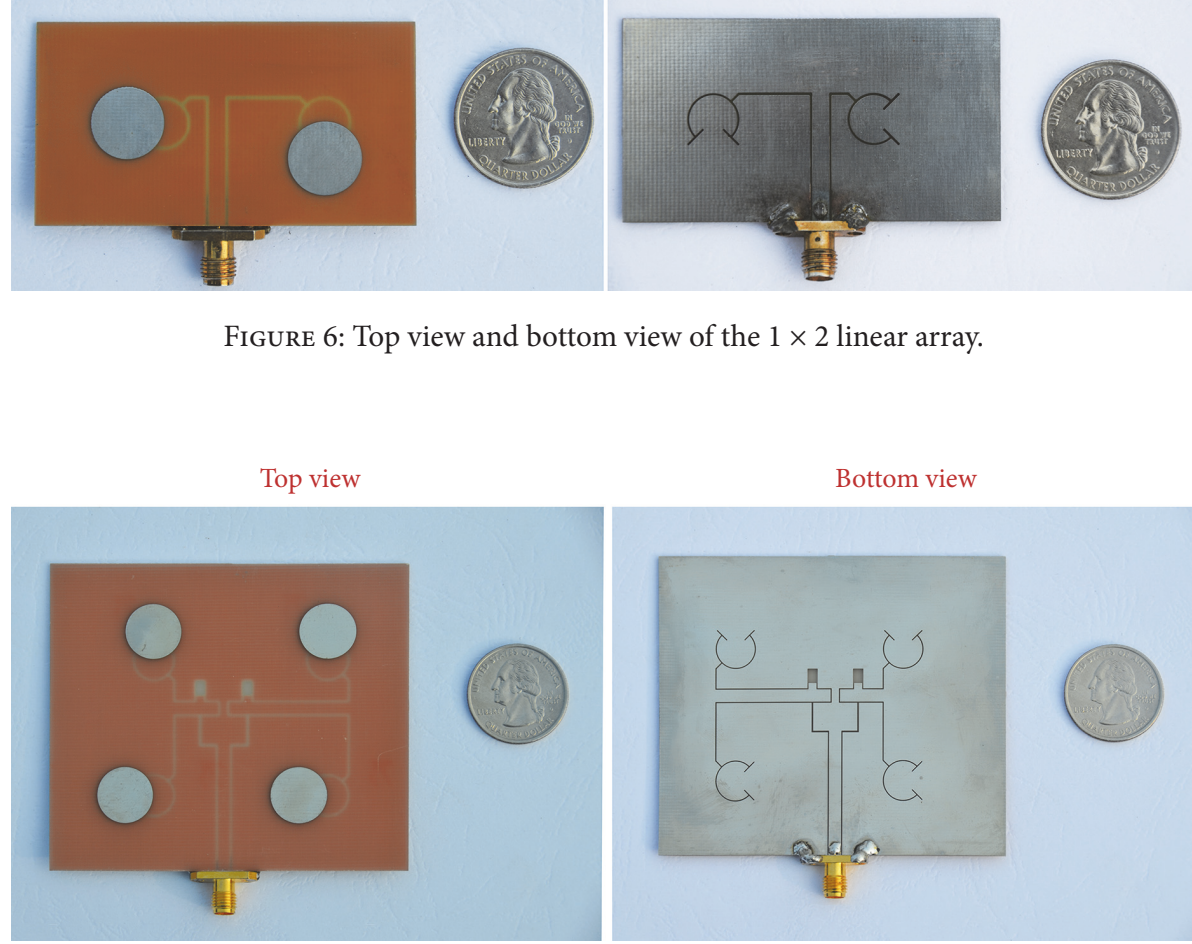

Bottom view

FIgURE 7: Top view and bottom view of the $2 \times 2$ array.
Bottom view

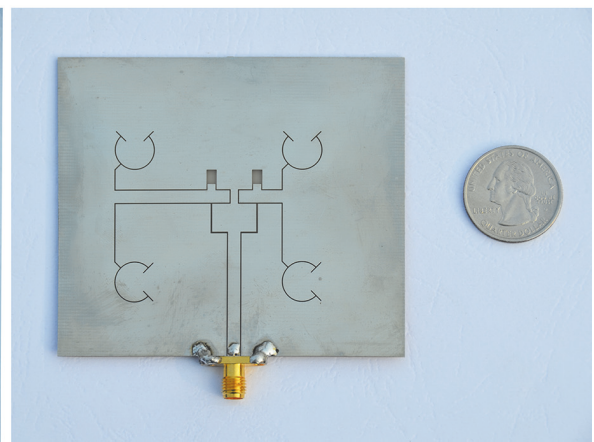




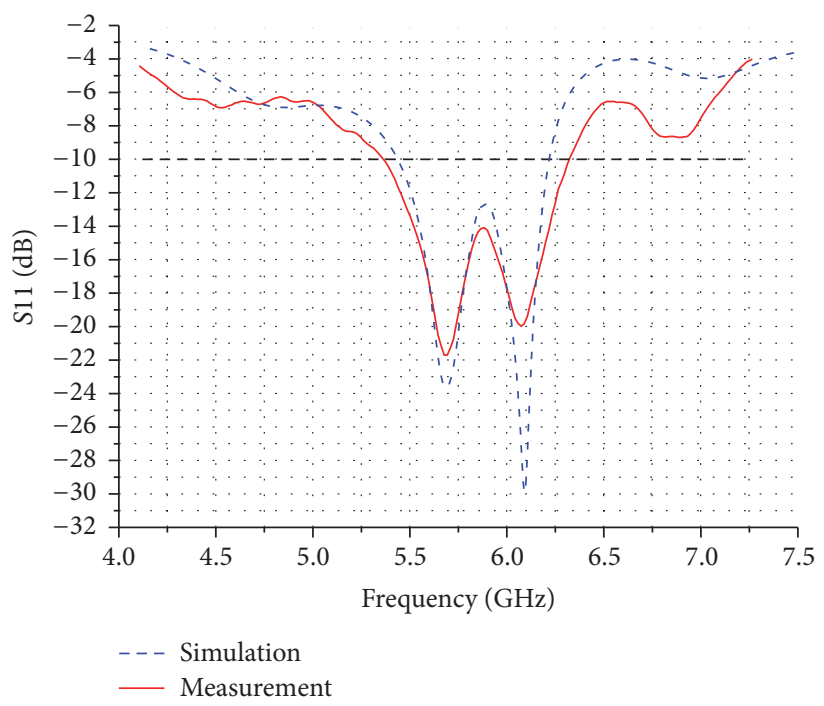

Figure 8: Measured and simulated $|S 11|$ of the $1 \times 2$ linear array.

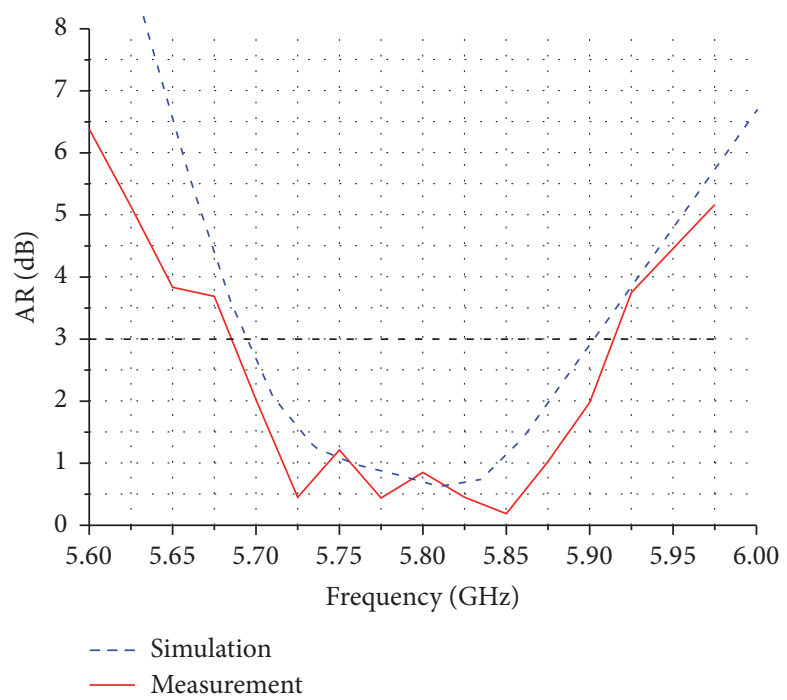

FIgURE 9: Measured and simulated AR of the $1 \times 2$ linear array.

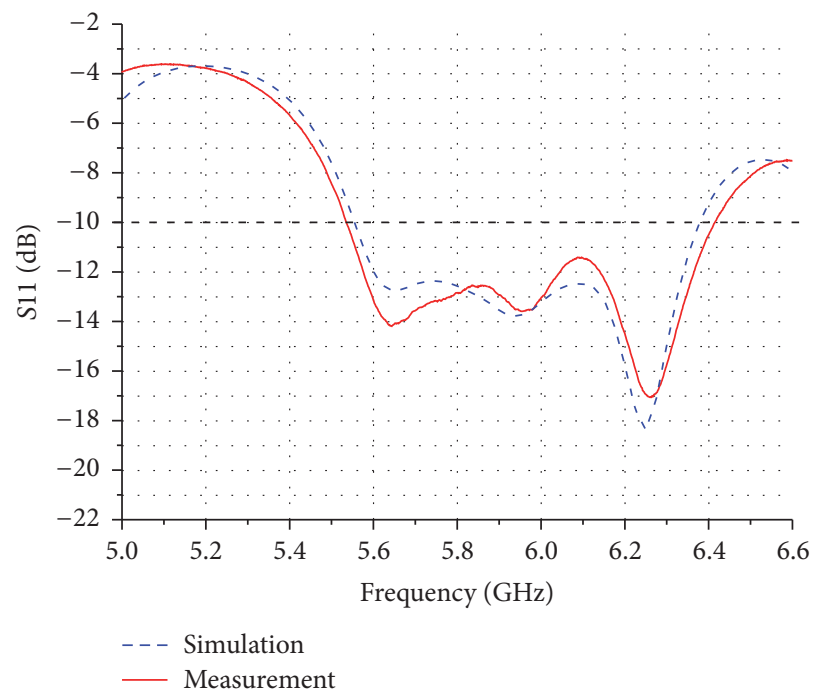

FIGURE 10: Measured and simulated $|S 11|$ of the $1 \times 2$ linear array. 


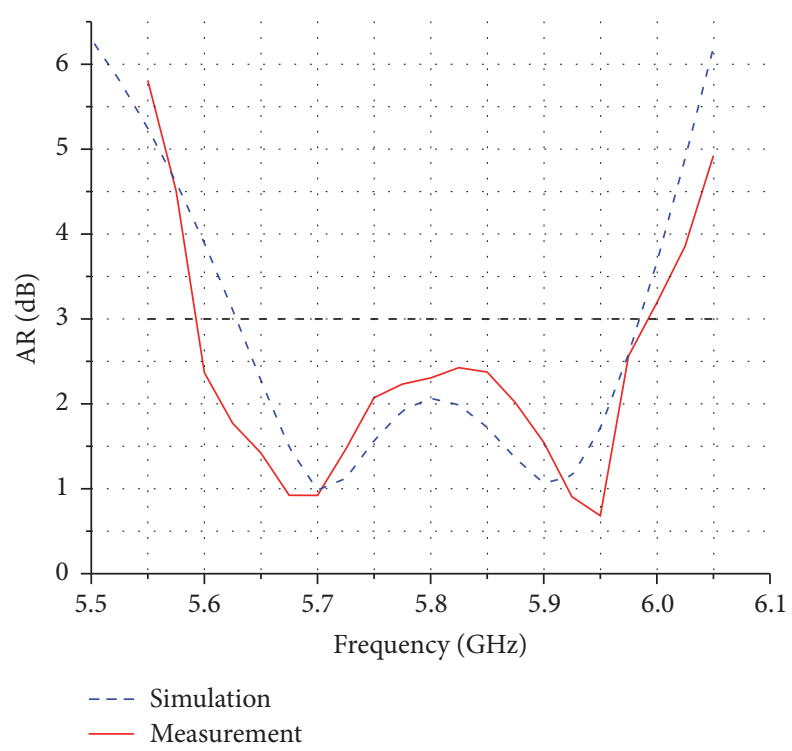

FIGURE 11: Measured and simulated AR of the $1 \times 2$ linear array.
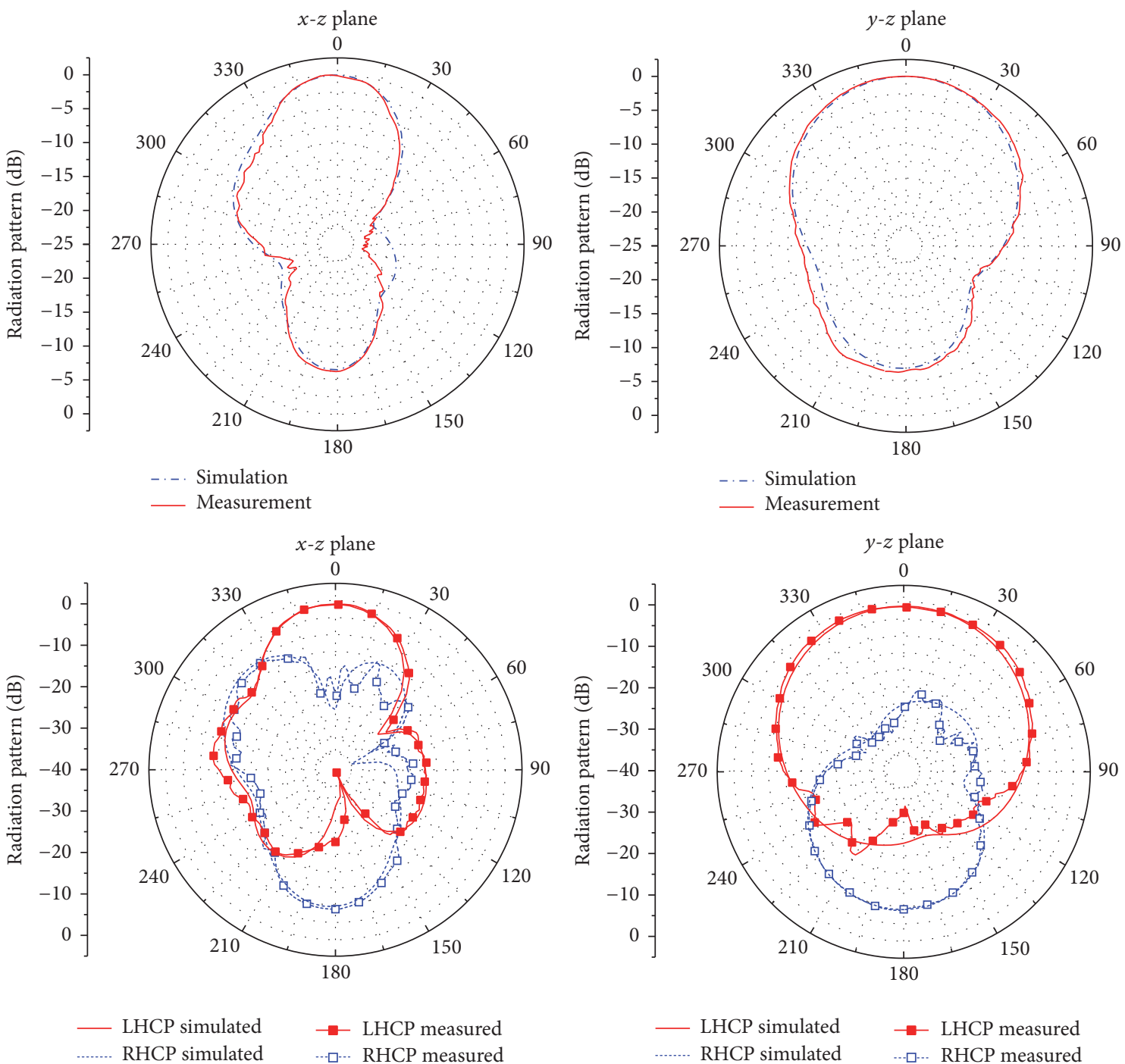

FIGURE 12: Measured and simulated radiation patterns and the copolar and cross-polar components of the $1 \times 2$ array. 

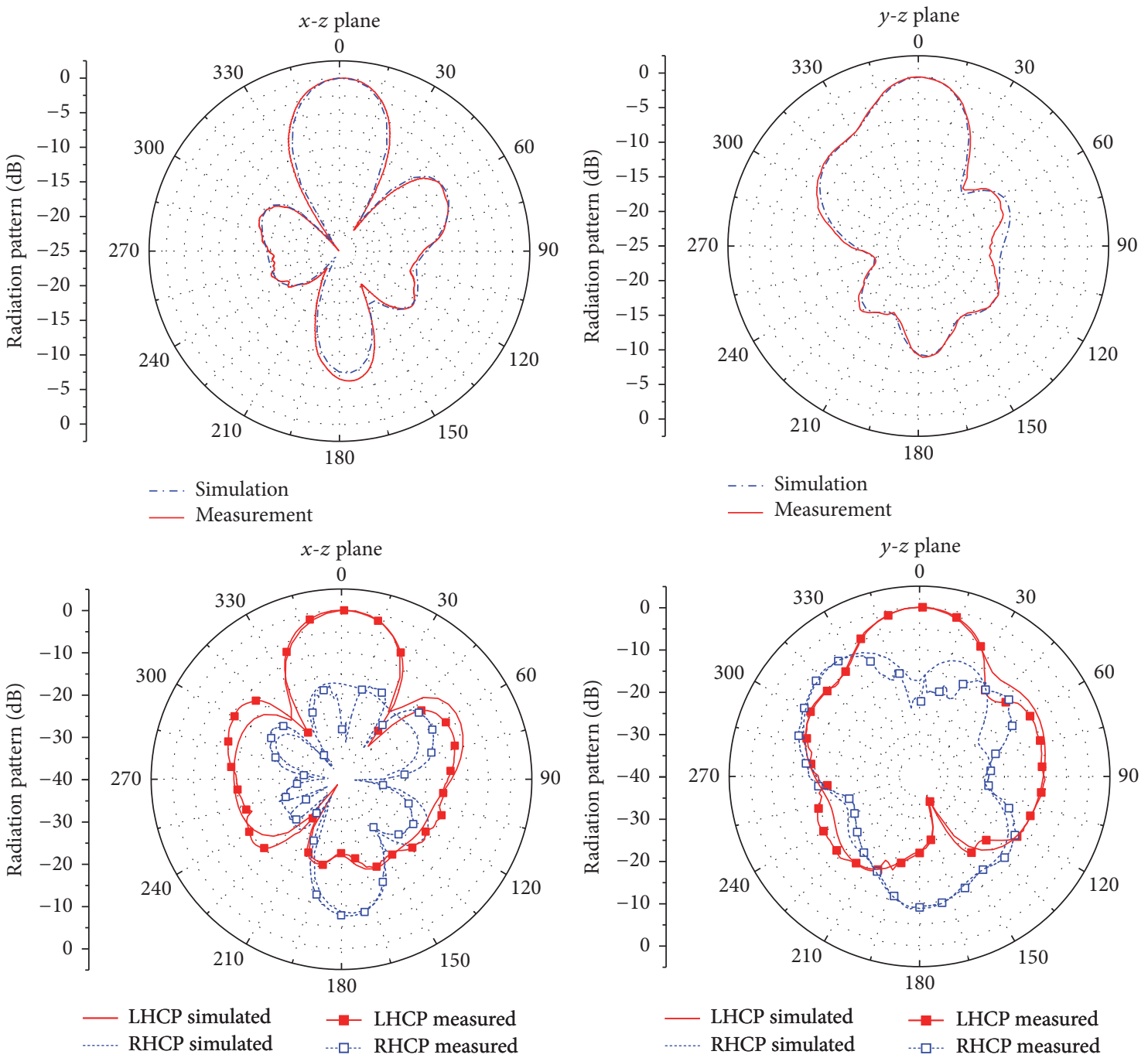

FIGURE 13: Measured and simulated radiation patterns and the copolar and cross-polar components of the $2 \times 2$ array.
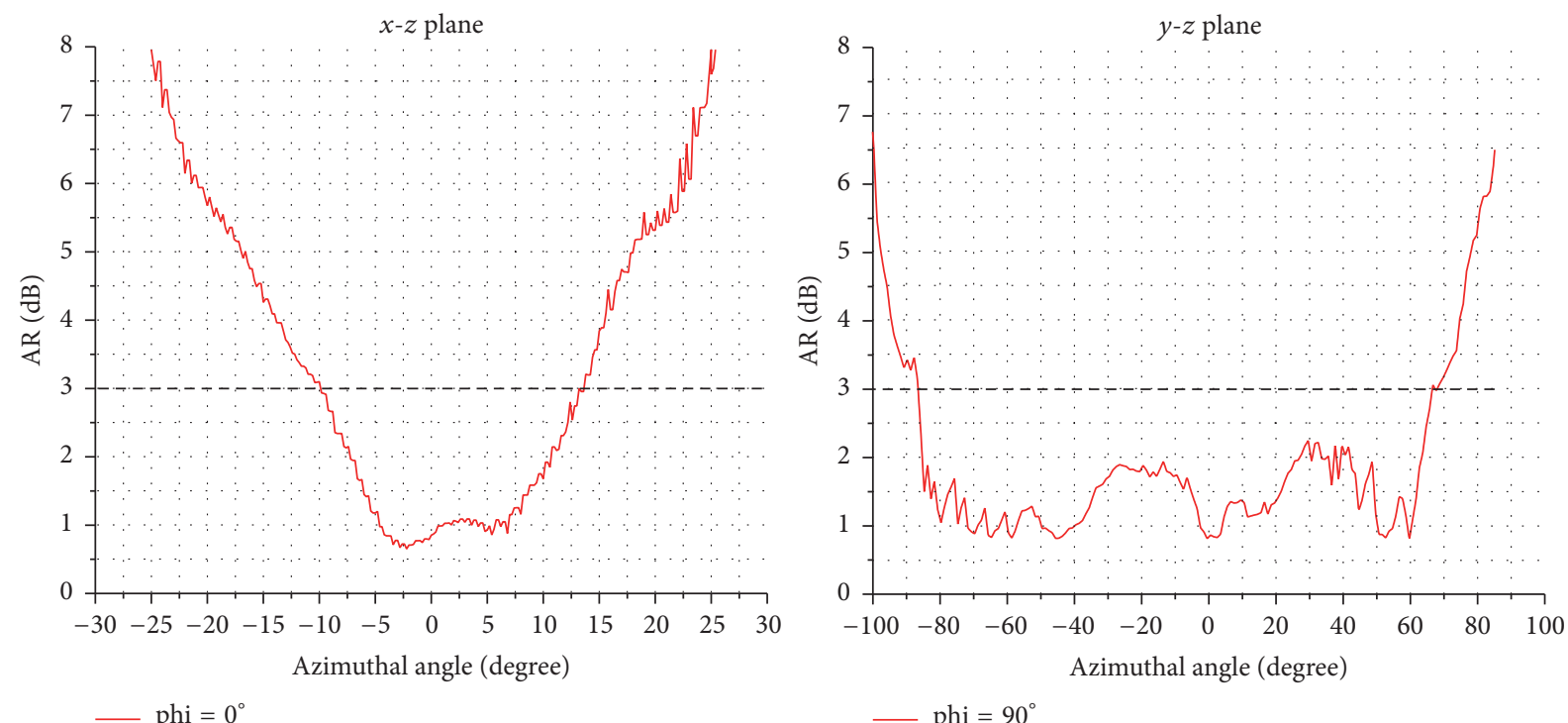

FIgURE 14: Measured AR against azimuth angle of the $1 \times 2$ linear array. 

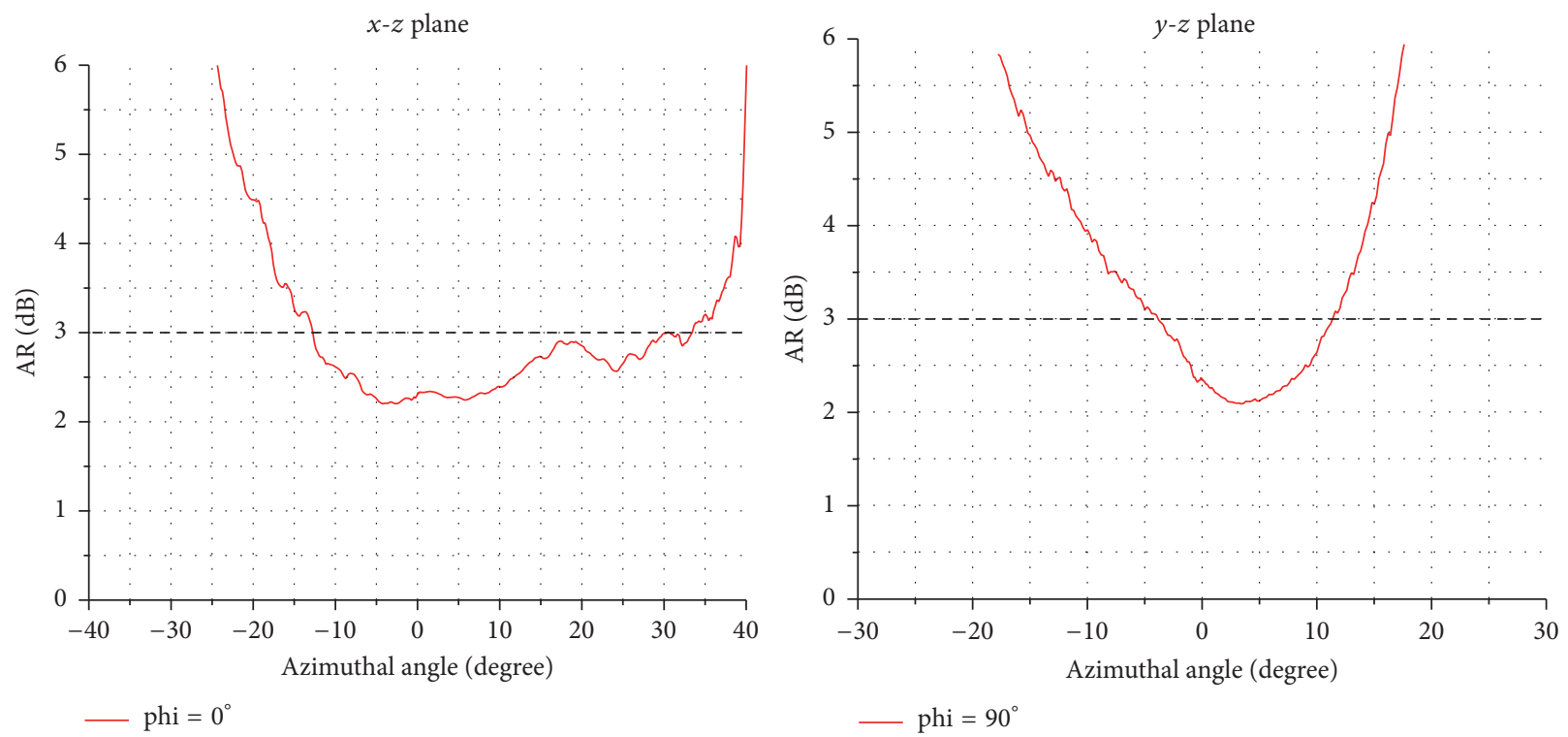

FIGURE 15: Measured AR against azimuth angle of the $2 \times 2$ array.

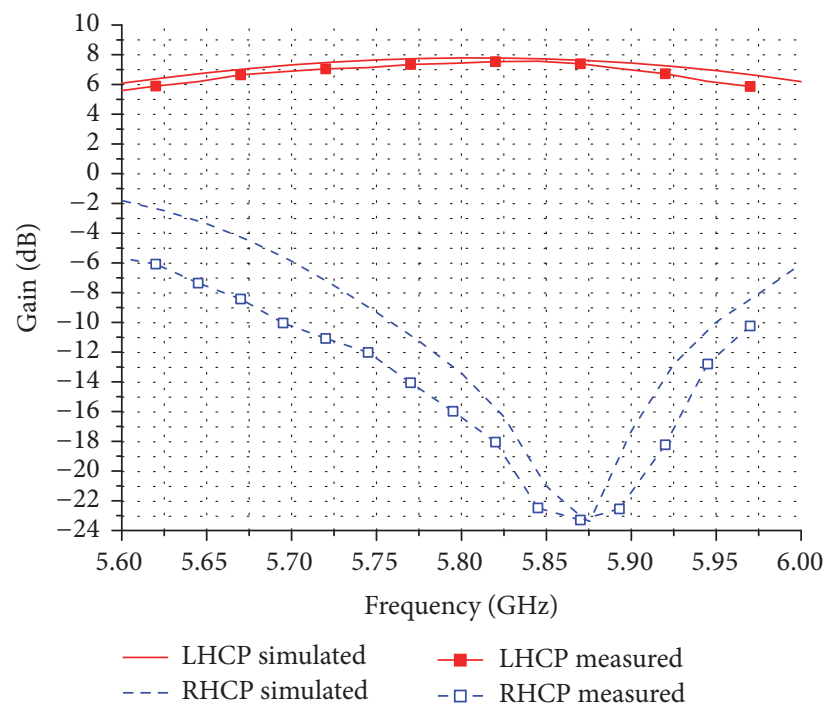

FIGURE 16: Simulated and measured LHCP gain and RHCP gain of the $1 \times 2$ linear array.

\section{Conclusion}

A novel CPW-slotline fed $1 \times 2$ linear antenna array and an improved $2 \times 2$ antenna array for circularly polarized radiation have been proposed in this paper. ANSYS HFSS 15.0 has been used to simulate these antenna arrays. The validity of this design has been established by comparing with the experimental results on $\left|S_{11}\right|$, axial ratios, radiation patterns, and gains. The present antenna arrays have simple geometries and are relatively easier to be fabricated because of

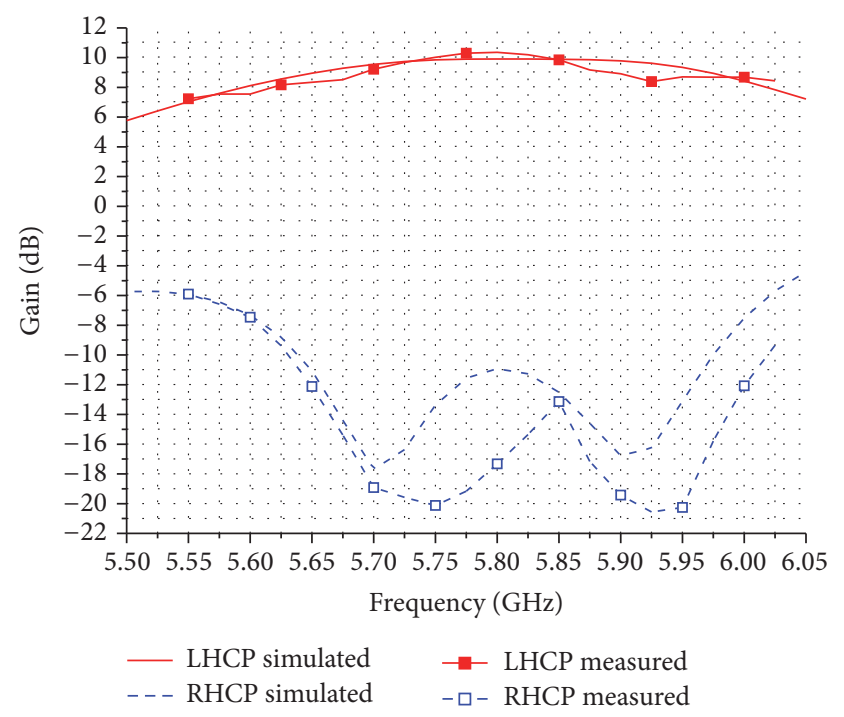

FIgURE 17: Simulated and measured LHCP gain and RHCP gain of the $2 \times 2$ array.

their lightweight design and single-layer structure. The proposed design is suitable for microwave power transmission system and intelligent transportation system. Additionally, the proposed antenna arrays can be extended to form a larger lightweight 2-dimensional array on a single thin substrate, as a higher array gain is required.

\section{Conflicts of Interest}

The authors declare that there are no conflicts of interest regarding the publication of this paper. 
TABLE 4: A comparison of the proposed array with other similar arrays.

\begin{tabular}{lcccccc}
\hline \multirow{2}{*}{ Antenna array } & \multirow{2}{*}{$f_{c}(\mathrm{GHz})$} & \multirow{2}{*}{$\mathrm{CP}$ or LP } & \multicolumn{2}{c}{ Bandwidth } & Measured max gain $(\mathrm{dB})$ & Size $\left(\lambda_{0}{ }^{2}\right)$ \\
\hline Our design & 5.80 & $\mathrm{CP}$ & $14.74 \%$ & $6.91 \%$ & 10.11 & $2.34 \lambda_{0}{ }^{2}$ \\
Reference [15] & 25.25 & $\mathrm{CP}$ & $13 \%$ & $12 \%$ & 10 & $1.46 \lambda_{0}{ }^{2}$ \\
Reference [18] & 4.07 & $\mathrm{CP}$ & $7.3 \%$ & $4.4 \%$ & 12.23 & $2.98 \lambda_{0}{ }^{2}$ \\
\hline
\end{tabular}

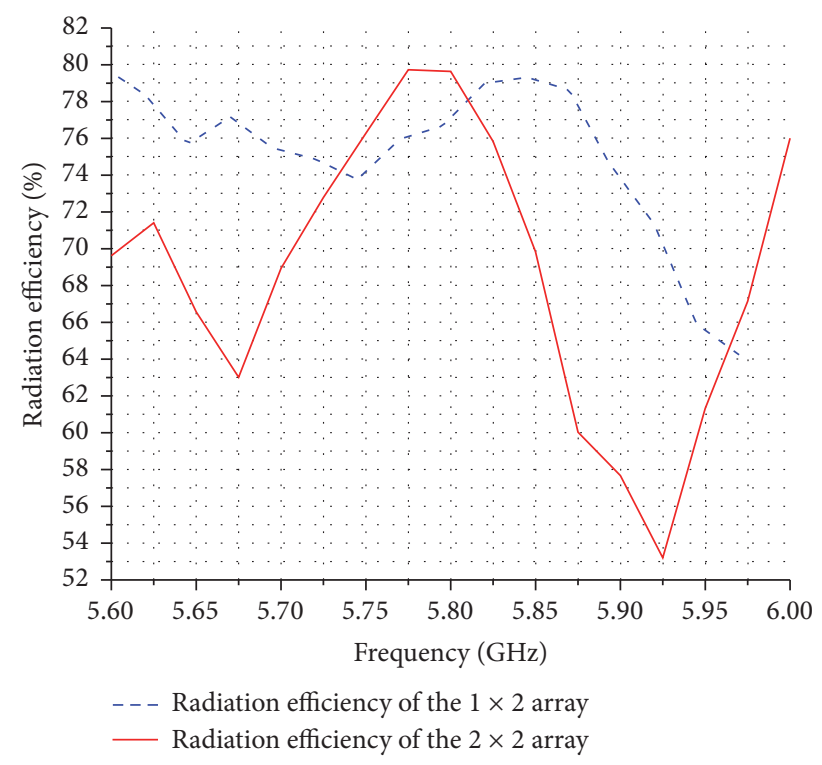

FIGURE 18: Measured radiation efficiencies of the $1 \times 2$ linear array and the $2 \times 2$ array.

\section{Acknowledgments}

The work is supported by National Basic Research Program of China (nos. 2013CB328900 and 2013CB328902).

\section{References}

[1] S. Maddio, "A compact two-level sequentially rotated circularly polarized antenna array for C-band applications," International Journal of Antennas and Propagation, vol. 2015, Article ID 830920, 10 pages, 2015.

[2] T. Varum, J. N. Matos, P. Pinho, and R. Abreu, "Nonuniform broadband circularly polarized antenna array for vehicular communications," IEEE Transactions on Vehicular Technology, vol. 65, no. 9, pp. 7219-7227, 2016.

[3] X. Gao, Z. Shen, and C. Hua, "Conformal VHF log-periodic balloon antenna," IEEE Transactions on Antennas and Propagation, vol. 63, no. 6, pp. 2756-2761, 2015.

[4] C. Wang and W. Tsai, "Microstrip open-slot antenna with broadband circular polarization and impedance bandwidth," IEEE Transactions on Antennas and Propagation, vol. 64, no. 9, pp. 4095-4098, 2016.

[5] F.-J. Huang, T.-C. Yo, C.-M. Lee, and C.-H. Luo, "Design of circular polarization antenna with harmonic suppression for rectenna application," IEEE Antennas and Wireless Propagation Letters, vol. 11, pp. 592-595, 2012.
[6] L. B. K. Bernard, Nasimuddin, and A. Alphones, "AN e-shaped slotted-circular-patch antenna for circularly polarized radiation and radiofrequency energy harvesting," Microwave and Optical Technology Letters, vol. 58, no. 4, pp. 868-875, 2016.

[7] J. M. Kovitz and Y. Rahmat-Samii, "Using thick substrates and capacitive probe compensation to enhance the bandwidth of traditional CP patch antennas," IEEE Transactions on Antennas and Propagation, vol. 62, no. 10, pp. 4970-4979, 2014.

[8] Y. M. Madany, "Design and analysis of multiband annular slot antenna with metamaterial array structure for intelligent transportation communication systems," in Proceedings of the IEEE Antennas and Propagation Society International Symposium (APSURSI '13), pp. 1798-1799, Orlando, Fla, USA, July 2013.

[9] R. Cao and S.-C. Yu, "Wideband compact CPW-fed circularly polarized antenna for universal UHF RFID reader," IEEE Transactions on Antennas and Propagation, vol. 63, no. 9, pp. 4148-4151, 2015.

[10] S. Nikolaou and M. A. B. Abbasi, "Miniaturization of UWB antennas on organic material," International Journal of Antennas and Propagation, vol. 2016, Article ID 5949254, 12 pages, 2016.

[11] R. Bhattacharya, R. Garg, and T. K. Bhattacharyya, "A compact Yagi-Uda type pattern diversity antenna driven by CPW-fed pseudomonopole," IEEE Transactions on Antennas and Propagation, vol. 64, no. 1, pp. 25-32, 2016.

[12] S. Nikolaou, M. M. Tentzeris, and J. Papapolymerou, "Study of a conformal UWB elliptical monopole antenna on flexible organic substrate mounted on cylindrical surfaces," in Proceedings of the IEEE 18th International Symposium on Personal, Indoor and Mobile Radio Communications (PIMRC'07), pp. 1-4, Athens, Greece, September 2007.

[13] B. Kim, S. Nikolaou, G. E. Ponchak, Y.-S. Kim, J. Papapolymerou, and M. M. Tentzeris, "A curvature CPW-fed ultrawideband monopole antenna on liquid crystal polymer substrate using flexible characteristic," in Proceedings of the IEEE Antennas and Propagation Society International Symposium (APS '06), pp. 1667-1670, Albuquerque, NM, USA, July 2006.

[14] D. Hua, S.-S. Qi, W. Wu, and D.-G. Fang, "CPW-fed printed antenna array with conical beam," IEEE Transactions on Antennas and Propagation, vol. 64, no. 3, pp. 1096-1100, 2016.

[15] E. A. Soliman, S. Brebels, E. Beyne, and G. A. E. Vandenbosch, "Sequential-rotation arrays of circularly polarized aperture antennas in the MCM-D technology," Microwave and Optical Technology Letters, vol. 44, no. 6, pp. 581-585, 2005.

[16] T. Zhang, W. Hong, and K. Wu, "Analysis and optimum design of sequential-rotation array for gain bandwidth enhancement," IEEE Transactions on Antennas and Propagation, vol. 63, no. 1 , pp. 142-150, 2015.

[17] A. B. Smolders and H. J. Visser, "Low side-lobe circularlypolarized phased arrays using a random sequential rotation technique," IEEE Transactions on Antennas and Propagation, vol. 62, no. 12, pp. 6476-6481, 2015. 
[18] I.-J. Chen, "CPW-fed circularly polarized $2 \times 2$ sequentially rotated patch antenna array," in Proceedings of the 2005 AsiaPacific Microwave Conference Proceedings (APMC '04), pp. 1-3, IEEE, Suzhou, China, December 2005.

[19] E. A. Soliman, P. Pieters, E. Beyne, and G. A. E. Vandenbosch, "Suppression of the parasitic modes in CPW discontinuities using MCM-D technology-application to a novel 3-db power splitter," IEEE Transactions on Microwave Theory and Techniques, vol. 46, no. 12, pp. 2426-2430, 1998.

[20] A. M. H. Nasr and A. M. E. Safwat, "Air-bridge free coplanar waveguide power divider," in Proceedings of the 45th European Microwave Conference (EuMC '15), pp. 474-477, IEEE, Paris, France, September 2015.

[21] B. Y. Toh, R. Cahill, and V. F. Fusco, "Understanding and measuring circular polarization," IEEE Transactions on Education, vol. 46, no. 3, pp. 313-318, 2003. 


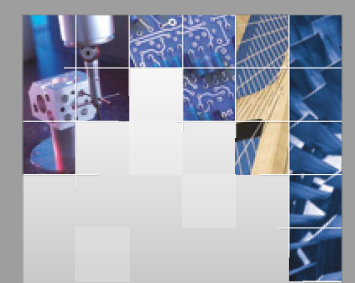

\section{Enfincering}
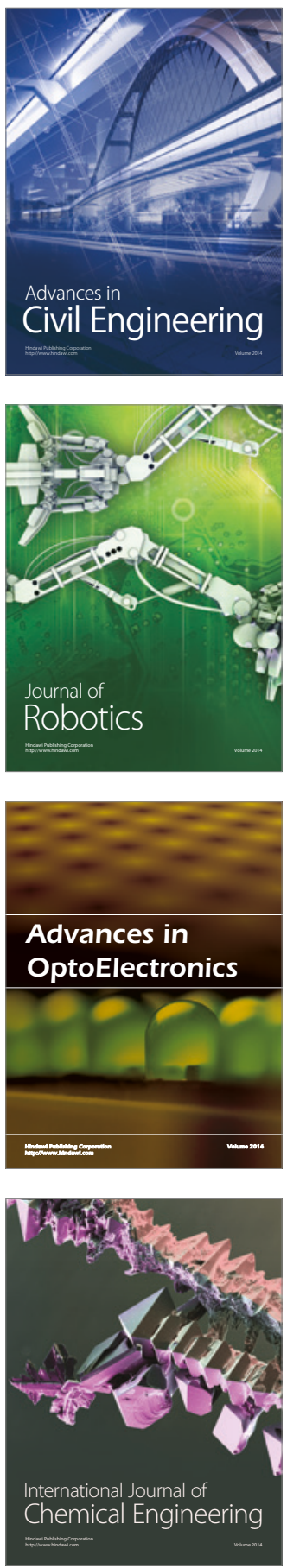

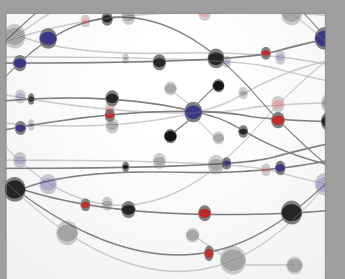

The Scientific World Journal

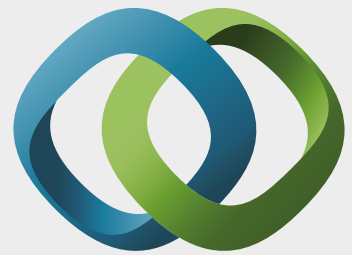

\section{Hindawi}

Submit your manuscripts at

https://www.hindawi.com
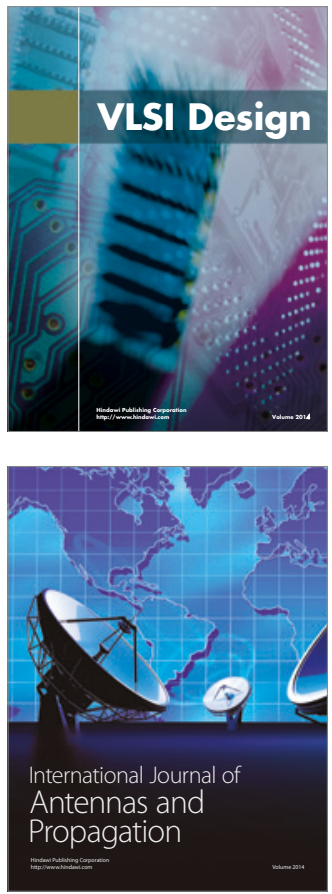

\section{Rotating}

Machinery
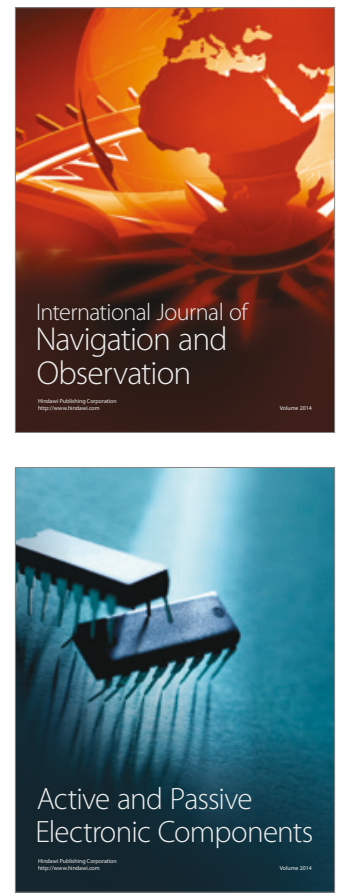
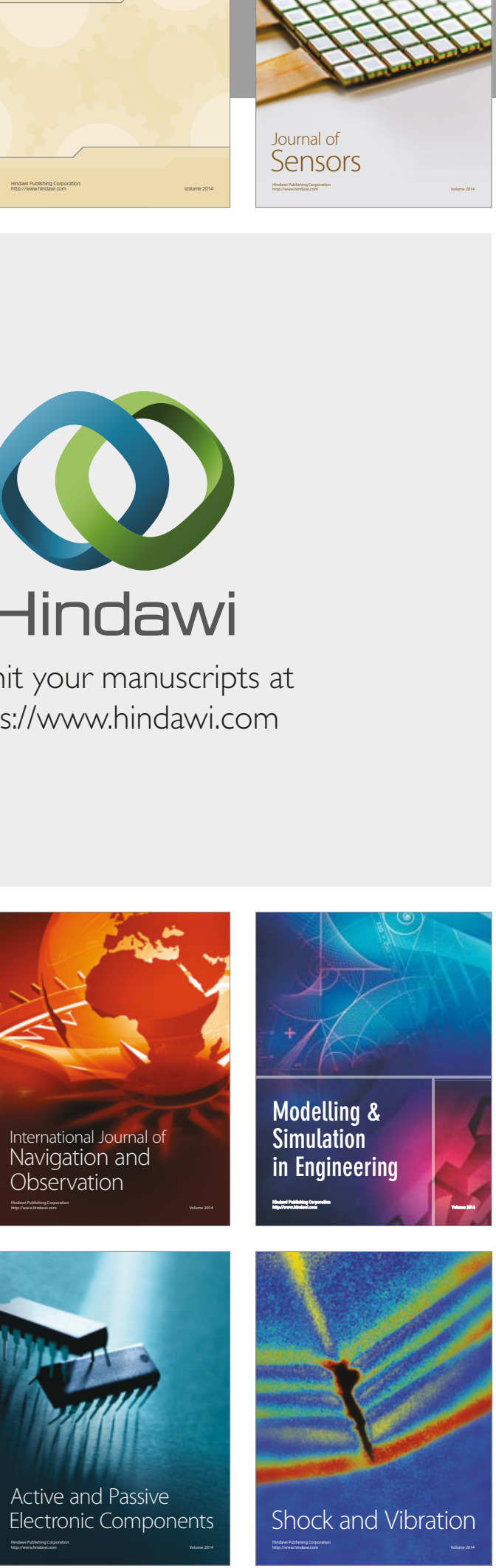
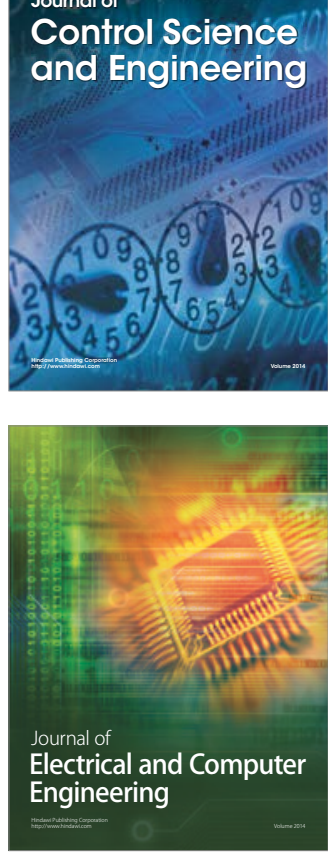

Distributed

Journal of

Control Science

and Engineering
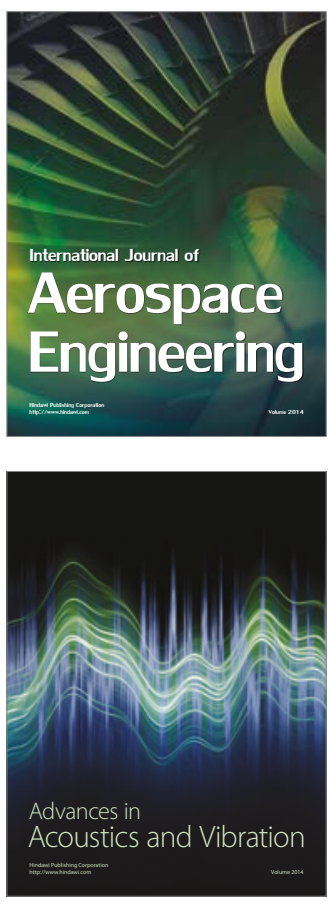

Sensor Networks 